discussed their written accounts with colleagues to identify and record:

- key words that characterise the experience of spiritual need; and

- indicators (objective and subjective) of spiritual need.

Finally, participants wrote a brief, summary description of the spiritual need, which they further refined with their colleagues. Result The pilot identified refinements to improve the methodology as an effective way of gathering data useful in building a typology of spiritual need.

Application to hospice practice With evidence growing that attending to spiritual needs has a beneficial effect on health outcomes (Koenig et al 2012), a clearer understanding of what constitutes 'spiritual need' is likely to have direct impact on patient care and health outcomes.

\section{P150 DEATH ANXIETY RECOGNITION IN A PALLIATIVE CARE SETTING}

Erzsi Nemeth, Ros Taylor, Sarah Russell. Hospice of St Francis, Berkhamsted, UK

\subsection{6/bmjspcare-2013-000591.172}

Death anxiety is the "feeling of dread, apprehension or solicitude (anxiety) when one thinks of the process of dying, or ceasing to 'be'." (1)

Introduction Recognition of death anxiety is important in hospice care, but assessment and management is often down to subjective interpretation and personal skills.

There are a number of formal death anxiety scales $(2,3)$ with an acceptable level of reliability, but these are not routinely used in hospice work. Informal assessment of death anxiety is based on narrative disclosure within a holistic assessment and covert death anxiety is often missed. (4). Generalised anxiety often masks the more specific concerns of 'death anxiety' - and the treatment may differ.

Death anxiety can be managed with psychological interventions specifically aimed at existential distress, spiritual support, and facilitation of open discussions regarding death. These include 'meaning- based' interventions and legacy work.

Standard health anxiety approaches within a cognitive behavioural approach (CBT) have been adapted to treat death anxiety with good effect (5); however a specific death anxiety model is not available.

As part of a Masters Degree in Cognitive Behavioural Therapy I plan to research and design a model of care for death anxiety that can be used in front-line palliative practice. The following work is a baseline survey to underpin the research.

Aim To establish current level of understanding, assessment and management of death anxiety at the Hospice of St Francis.

Method Inpatient staff completed an anonymous questionnaire to highlight :

- their understanding of the concept of death anxiety

- confidence staff feel in diagnosing and assessing death anxiety.

- subsequent management of death anxiety.

These questions consisted of rating scales and narrative responses. Future work

- To develop an assessment tool to detect death anxiety in a hospice setting,

- To develop a CBT model specifically for the treatment of death anxiety.

\section{P151 REAL TIME REPORTING PILOT IN END OF LIFE CARE}

${ }^{1}$ Jane Bake, ${ }^{2}$ Marie Cooper. 'St Barnabas Lincolnshire Hospice, lincoln, england, ${ }^{2}$ Marie Curie Cancer Care, ${ }^{3} \mathrm{Help}$ the Hospices, ${ }^{4}$ National End of life Care Programme, ${ }^{5}$ United lincolnshire Hospitals, ${ }^{6}$ Lincolnshire NHS Community services, ${ }^{7}$ Order of St Johns Care Trust

\subsection{6/bmjspcare-2013-000591.173}

Background It is acknowledged that to date, capturing meaningful and timely feedback from patients within the last year of life, and their families, remains a challenge.

Project aim and objectives The objectives of the project were to ascertain the acceptability and usefulness of a real time survey and reporting system to capture the experience of patients, families and carers receiving end of life care.

Organisations within Lincolnshire were invited to join the pilot and four different care settings, where end of life care is commonly provided were engaged; care home, persons own home, hospice and hospital.

Approach Survey questions were tailored to each care setting with volunteers and staff inviting participants to use a hand held 'ipad' device to feedback their experience of care; alternative options, such as web link and paper survey, were also offered. Outcomes and application

- The pilot was successfully implemented across all four different care settings.

- The use of the devices and the length of the survey were acceptable to individual receiving care and their family member.

- The trial of a reworded 'family \& friends 'question with those at the end of life proved acceptable to the majority of users

The role of the volunteer was instrumental in engaging participants. Volunteers expressed satisfaction and reported back on the added value of one to one engagement with survey participants.

- Anecdotal feedback from the volunteers and staff suggested that patients and carers were happy to participate and expressed enjoyment in taking part. "Patients appreciate the opportunity to speak to someone and to have their voice heard as well as trying new technology"

- Provides timely, concise and meaningful information to service providers

- Provides opportunities for organisations to benchmark end of life care county-wide

- Next phase will seek to inform on further learning for a national roll out

\section{P152 MAKING USER INVOLVEMENT HAPPEN}

Frankie Dee, Jutta Widlake. St Luke's Hospice, Plymouth, United Kingdom

10.1136/bmjspcare-2013-000591.174

Background Stakeholders need a voice that is focussed on the quality of a service rather than numbers. They want to provide feed-back and make recommendations developing a true partnership. User involvement can provide this process. A group was set up 3 years ago to develop this and has now moved from "meeting" to "making happen"

Aim

- Help in identifying areas requiring improvement 